\title{
Ng, Karen. Hegel's Concept of Life. Oxford: Oxford University Press, 2020, 319 pp.
}

\author{
Andrés Ortigosa ${ }^{1}$ \\ Universidad de Sevilla, España
}

For the last decades, scholars have been researching Hegel and Kant. Broadly speaking, they consider a continuity between Hegel's philosophical system and Kant's epistemology. Surprisingly, Karen Ng critiques some of these philosophers but also defends this interpretative tradition. To do this Ng considers the relevance of the concept of "life" as a required condition for a correct interpretation of Hegel's Science of Logic. This is truly a reinterpretation.

Strictly speaking, Hegel's concept of life addresses three topics (4). The first is about what self-consciousness is. Then, how it operates on the cognition process (in opposition to Brandom and Pippin's ideas). The second is about self-determination (or freedom) and how to make it compatible with nature. In other words, the problem of reconciliation between freedom and nature in post-Kantian philosophy. The third topic is Kantian a priori problem. In order to explain Ng's answers to these three topics, I will outline each chapter. The book's chapters are organized into two sections. The first section of the book is about Kant's influents on Hegel (chapters 2 and 3). The second section is the reinterpretation of Science of Logic (chapters 4, 5, 6, 7, and 8).

In chapter $2 \mathrm{Ng}$ considers Hegel as a follower of Kant's epistemological ideas (as Friedrich Beiser and other scholars did). But she focus- 
es on Hegel's attention on "purposiveness" in the Kantian first and third Critique. To expose this, Ng rethinks Kant's conception of purposiveness. Purposiveness is a principle that allows and empowers our judgement, preventing arbitrariness unification of concepts with objects. But our empowered judgement could be a teleological judgement or a mechanistic judgement. Ng states that the most important idea underlined on purposiveness is "internal purposiveness". This capital notion expresses supremacy of the teleological judgement subsuming the mechanistic judgement.

In chapter 3, $\mathrm{Ng}$ vindicates the importance of Differenzschrift. Based on this writing, Ng exposes the "identity thesis". It seems that for Ng identity thesis is the core of Hegelian philosophy. The identity thesis is an argumentative strategy outlined by Hegel to transform the reciprocity between Kantian judgement and purposiveness into reciprocity between self-consciousness and life (68). This is the origin of the Hegelian notion of life. Also, it is an assumption of Kant's philosophy.

In chapter 4, 5, 6, 7 and $8 \mathrm{Ng}$ rethink the Science of Logic from the concept of life provided by chapter 3 . In chapter 4 she analyses the immanent deduction, identifying it with the genesis of the Concept. It is the "attempt to provide, in the logical context, a series of arguments for the constitutive character of inner purposiveness for any account of self-conscious conceptual activity whereby determinations of thinking have the power to determinate activity" (126). In a speculative sense, there is a sort of identity between the rational and the actual. This identity is called actuality (Wirklichkeit) (which answers to the mind-world problem). According to Ng, Hegel's Concept is the same as Kantian purposiveness but adding the notion of actuality. This allows us to rethink the expression "life of the Concept". This expression supports the transition from substance to subject in two ways. One way, following Aristotle, is the explication about why we could apprehend a living, self-caused and active substance. The second way is the actualization of self-conscious guided by Spinoza (160-161). These two ways enable Hegel to propose a subjective logic.

In chapter $5 \mathrm{Ng}$ exposes the subjective Concept. She defines Subjective Logic as an exploration of the form and operation of thoughts. Then is Hegel's own critique of judgement. As limits and powers of judgement shows, there is "activity life" (as Ng refers). This "activity life" is under- 
lining a logical conception of life. Activity life is the actualization of the reasoning activities, as a syllogism. In her view, syllogism's determination begins as the middle term. But they are completed by the form of the Concept since "once the mediating element is realized as the activity of the Concept, subjectivity transitions into objectivity, and Hegel`s discussion moves to a consideration of the reality of the Concept under the headings of mechanism, chemism, and teleology" (216). This process of determination starts from mechanism to chemism, and then from chemism to teleology. In this process, $\mathrm{Ng}$ discovers that reality has the shape of an internal purpose in teleology. Then there is a fulfilled relation between subjective Concept and reality through teleology. This correspondence is called by Hegel "Idea".

In chapter $6 \mathrm{Ng}$ explores life in the objective Concept. Objective reality can be understood as a process of the self-determination of the Concept. $\mathrm{Ng}$ brilliantly demonstrates the transition from subjectivity to objectivity is following the same patterns as Hegel's ontological proof for the existence of God. The reasoning could be sum up as: Humankind only knows the activity or works of God. These activities are the determination of God, what we usually call properties. Then, when we apprehend the activities of God, those activities are his being. This is like the objective Concept. The Concept has three determinations (mechanism, chemism, teleology). In consequence, they are manifestations of the same objective reality. Also, they are manifestations of reality which refer to the Concept (227). After this demonstration, Ng relates "external purposiveness" (a causal relation) to mechanism and chemism. External purposiveness is seen as a kind of violence. "Violence" is the power exercised by objective reality which destroys the capacity of an object to be itself a subject (230). This provokes a cognitive tension between reality and Concept. But teleology is the key notion. Teleology is the assumption of the "activity and reality of the Concept as self-determination" (233). Then there is an inner constitution of objects. Ng explains this abstract point with a great example: When we visit a friend at the hospital is an act that reflects the power of friendship in external objectivity, and this constitutes ourselves (as subjects) as good friends through the self-determining activity of the subject (240). Thereby Ng shows how internal purposiveness is needed for Hegel. Probably the au- 
thor could explain more detailed how this objective judgement of Concept is related to the Idea. I think that in her book there is an argumentative gap here because the connection between the objective judgement of the Concept and the Idea is not fully explored.

In chapter $7 \mathrm{Ng}$ explains the different meanings of "Idea" in Science of Logic. Her analysis guides us to the consideration of the Idea as life. But it is a life that is in-itself and for-itself. This should be understood as self-actualization. For instance, self-actualization between unconsciousness and self-consciousness. When we realized something that is in our unconscious, it affects our self-consciousness. Then she discusses the end of the Science of Logic. To this end, there are two claims. The first one is that the Idea has a different status in comparison to other determinations of thought. Life, cognition, and the absolute Idea (the three parts of the Idea) are the ground of the thought-determinations of Science of Logic. The second is about the "duplication" of the Idea. Duplication will be "manifest as immediate in life and as thought, self-consciousness, and spirit in cognition" (249). Ng considers that the duplication of the Idea is Hegel's attempt to restore the Kantian doctrine of the two stems of knowledge. It resolves the Kantian problem of the combination of concepts and intuitions. Intuitions and concepts have different kinds of unities, in the absence of a common principle. Thereby Hegel thinks that Kantian intuition needs a re-examination. This leads Ng to consider Faith and Knowledge as a key text. In this text, he exposes the immediacy of self-consciousness cognition. This is compared by $\mathrm{Ng}$ as the function of life in the Science of Logic. Following this interpretation, "Concept and objectivity are immediately manifest in their unity and division" (254). But concepts are mediated. In contrast, Hegel considers concepts and external reality as immediately manifested in their division. But also, it is unified constituting an overcoming of the Kantian approach. And at this point, life is, again, a capital point. Life enables an immediate unity between the Concept and objectivity. From life, the Idea seems as a priori schema in its three moments. The first moment of the Idea in life is called corporality, which is for Hegel the capacity to focus on sensibility, as a capability for receptivity. This is an immediate sense of our self. The second moment is about externality. At this moment, the objective world is presupposed. Ng clarifies that externality is a necessary condition 
for judgement caused by reciprocation. But a reciprocation between subjectivity and objectivity, producing self-certainty. The third moment is the called genus. It is the presupposition of a life process. In this process, an individual reproduces itself and vice versa. Then, the process of the genus presupposes the life process of the individual. These three moments of life provoke a dialectical relation between life and cognition which will be explored in the next chapter.

Chapter 8 is a development of her thesis of life as an a priori schema. It is a complex interpretation. The main difference with chapter 7 is that in the previous chapter life was an immediate Idea. In this chapter, Ng exposes life as a producer of self-conception. This means a cognition step. Ng first explains the limits of theoretical cognition based on finite cognition (Verstand). This limitation conceives the thing-in-itself as separated from the notion of truth. The reason is that, for finite cognition, the thing-in-itself is inapprehensible by concepts. Also, there is a practical cognition. This cognition is determined by our will and guided by intuitions. But it cannot find anything as truth in the external world. Both cognitions, theoretical and practical, are unified by Hegel in a notion called "absolute Idea". Then, "absolute Idea" is a logical idea of life because there is no separation. At the same time, there is an a priori schema internal to the method allowing self-consciousness to actualize itself (277). Therefore, the absolute method is a dialectic between life and cognition. To summarize, the absolute method is the growth of life activities as forms of self-consciousness. And its ground is a logical concept of life.

To conclude, I consider that Ng's book is a brilliant exposition. It opens a new reading of Science of Logic. It is difficult to say this because it is no common in a review but to be honest, I have no disagreements with $\mathrm{Ng}$. She properly convinces me. And probably this will happen to many readers because Hegel's Concept of Life is a masterpiece. One of the best books on Hegel that I have read ever. 